\title{
WHY LEGAL THEORY IS POLITICAL PHILOSOPHY
}

\author{
William A. Edmundson* \\ Georgia State University
}

The concept of law is not a theorist's invention but one that people use every day. Thus one measure of the adequacy of a theory of law is its degree of fidelity to the concept as it is understood by those who use it. That means "saving the truisms" as far as possible. There are important truisms about the law that have an evaluative cast. The theorist has either to say what would make those evaluative truisms true or to defend her choice to dismiss them as false of law or not of the essence of law. Thus the legal theorist must give an account of the truth grounds of the more central evaluative truisms about law. This account is a theory of legitimacy. It will contain framing judgments that state logical relations between descriptive judgments and directly evaluative judgments. Framing judgments are not directly evaluative, nor do they entail directly evaluative judgments, but they are nonetheless moral judgments. Therefore, an adequate theory of law must make (some) moral judgments. This means that an adequate theory of law has to take a stand on certain (but not all) contested issues in political philosophy. Legal theory is thus a branch of political philosophy. Moreover, one cannot be a moral-aim functionalist about legal institutions without compromising one's positivism about legal norms.

Legal theory is a branch of political philosophy. This means that an adequate theory of law has to take a stand on certain contested issues in political philosophy. I do not say "on all contested issues," because there is more to political philosophy than what legal theory needs to address (although some deny even this limit). In making this overall point, I expand on some things I said about Scott Shapiro's book Legality ${ }^{1}$ in a review I wrote shortly after it came out. ${ }^{2}$ But I structure what I say using a framework drawn from Julie Dickson's Evaluation and Legal Theory. ${ }^{3}$ Dickson's book is about the methodology of analytical jurisprudence. Methodology should follow subject matter (in my opinion, which I suppose is the commonsense opinion) and not the reverse. But in the field of analytical legal philosophy, over recent years methodology has increasingly come to define the subject matter. I hope to make some contribution toward setting this straight, and

\footnotetext{
*I thank Kevin Toh, Bas van der Vossen, and Brian Bix for comments on an earlier draft.

1. Scott Shapiro, Legality (2011).

2. William A. Edmundson, Schmegality, 2 JURISPRUDENCE 273-291 (2011).

3. Julie Dickson, Evaluation And Legal Theory (2001).
} 
it would be a bigger contribution if I could persuade Shapiro and others to see the tasks of legal theory, or some of those tasks, as I do.

Analytical jurisprudence is an inquiry into the nature of law. Foremost among its tasks is to identify those necessary properties of law that capture its essence. Although Shapiro prefers to speak of "nature" rather than "essence," it is clear that he is part of this enterprise, ${ }^{4}$ to which Hans Kelsen, H.L.A. Hart, John Finnis, Joseph Raz, Jules Coleman, and numerous others have contributed. Even though Ronald Dworkin sometimes professed to confine his analysis to a certain legal culture, ${ }^{5}$ other remarks of his make it clear that his theorizing was offered as a contribution to analytical jurisprudence as well. ${ }^{6}$ According to Dworkin, any legal culture relevantly like anglophone legal culture will have a certain nature, consisting of certain features, such that, necessarily, a culture lacking those features is not a legal culture in the same sense as ours. Although the scope is narrower, the ambition is the same: to discover the nature of an important-even imperial—social practice.

It may be quixotic, as Brian Leiter ${ }^{7}$ and others argue, to go looking for "the nature" of anything that is an artifact; and law doubtlessly is an artifact, a human device or family of devices that is meant to serve and is thought to serve a kaleidoscopic variety of human purposes. I am setting aside this worry (and it is a serious one) by conditionalizing my thesis: if there is any fruitful endeavor such as that now going by the name "legal theory," it must be conceived as a branch of political philosophy (which, I grant, may turn out to be equally quixotic).

Recently, as I mention above, there has been an extensive debate about the proper methodology to employ in conducting an inquiry into the nature of law. The methodological debate has tended to dominate discussions of the theories of the nature of law that the methods produce. The methodological debate is often understood as pitting "evaluative" methodologies against "descriptive" ones. Rightly deploring this simplistic division, Dickson proposes a more refined classification. The binary headings conceal common ground and disguise or exaggerate crucial differences. The centerpiece of Dickson's elegant and influential analysis is a set of three theses (and I paraphrase):

4. SHAPIRO, supra note 1 , at 8-9, 223.

5. RonAlD DWORKIN, LAW's EMPIRE (1986), at 102.

6. As Brian Bix summarizes:

Dworkin makes a number of "analytical" or purportedly universal claims relating to lawe.g. that an interpretive approach is the right one for law (and other social and artistic practices) and that constructive interpretation is that right form of interpretation; also that all law is intended to constrain/justify state coercion.

Personal communication with author.

7. Brian Leiter. The Demarcation Problem In Jurisprudence: A New Case For Skepticism, 31 OXFoRD Journal of Legal Studies 663-677 (2011). 
Moral Evaluation Thesis [MET]: an adequate theory of law will include at least some morally evaluative propositions.

Moral Justification Thesis [MJT]: an adequate theory of law will represent law as morally justified.

Better Moral Consequences Thesis [BMCT]: The moral consequences of adopting a theory count in determining its adequacy as a theory of law. ${ }^{8}$

Key contributors can be sorted according to how they stand with respect to these theses; but first, notice that it is common ground that legal theory involves evaluation. Legal theory involves the kinds of evaluation that any theorizing does, that is, judgments of importance, relevance, coherence, adequacy, and even aesthetic-seeming judgments as to fruitfulness, simplicity, and elegance.

This is not in dispute. Nor is it disputed that evaluation-in some sense or senses to be clarified-is also woven into the object of study, the social practices that constitute the existence of law. Law is a familiar concept in everyday life; it is not a concept that the theorist imposes upon a subject of study. This yields at least one measure of the adequacy of a theory of law: it must be faithful to some degree to the concept as it is understood by those involved in the social practices that are the subject of investigation. This too is not in serious dispute, although there is dispute about which beliefs about law deserve to be regarded as part of the commonsense, or folk, conception of law, even if the inquiry is confined to the anglophone stage.

On the matter of classifying the major theorists, Dickson proposes the following, which I am expanding by adding Shapiro:

\begin{tabular}{llll}
\hline & MET & MJT & BMCT \\
\hline Raz & No & No & No \\
Shapiro & No & No & \\
Finnis & Yes & Yes & \\
Dworkin & Yes & Yes & No \\
\hline
\end{tabular}

A theorist's adherence to or rejection of the MET can be determined, Dickson argues, simply by asking whether that theorist employs directly evaluative propositions or only indirectly evaluative ones (at most). A statement is directly evaluative if and only if it is of the form, " $X$ is good," or entails some proposition of that form-where "good" is intended to mean morally good in some sense. A statement is indirectly evaluative if it is evaluative but is not directly evaluative. For example, " $X$ is important" is evaluative but only indirectly so, for what is important is not necessarily good in even a capacious moral sense. ${ }^{9}$ The utility of speaking of the directly evaluative instead of the morally evaluative is-presumably - that its contrast with indirectly

8. Dickson, supra note 3 , at 9 .

9. Id. at 51-56. 
evaluative allows one to map common ground more rapidly and to reserve nice questions about the precise nature of the moral for later, more focused deliberation. I find the distinction between direct and indirect rather mysterious, and I propose below a different way of testing adherence to the MET; but that can wait.

This survey helps to locate a potential Dworkinian charge, that Raz and certain other legal positivists implicitly embrace MET insofar as they ascribe certain functional advantages to law as their theories depict it. ${ }^{10}$ Shapiro falls within the reach of this indictment because he assigns a distinctive function to the comprehensive planning scheme that is law (and a moral-disputesettlement function, at that). ${ }^{11}$ At the same time, Shapiro stoutly defends a methodology that denies the MET. ${ }^{12}$ Finnis, by contrast, is happy to tout the inherent virtue of law as a means of solving coordination problems, and that is consistent with his embrace of the MET. ${ }^{13}$ But Raz, Dworkin might argue, cannot ascribe that or any similar virtue to law without thereby at least tacitly subscribing to MET. Nor can Shapiro, he might have added.

Dickson acquits Raz of this charge. ${ }^{14}$ One subscribes to the MET only insofar as one's theory includes or entails some directly evaluative proposition. Raz's does not, Dickson argues. Raz does make remarks about the functions that law, as he conceives it, might serve; and he does argue that unless law were as he says it is, it could not well serve those functions. ${ }^{15}$ But even on the assumption that Raz's overall theory commits him to the defense of those remarks, they are not directly evaluative propositions. They are indirectly evaluative. To say that $X$ is a (theoretically) important feature of social practice $Y$ is not to say that $X$ is a good-making (or a bad-making) feature of $Y$, Dickson correctly points out. ${ }^{16}$ And one can expand the point. To say that $X$ is a good-making feature of $Y$ in the eyes of participants in $Y$ is not to say that it is a good-making feature of $Y$. Furthermore, to say that $X$ is an important feature of $Y$ because it is a good-making feature of $Y$ in the eyes of participants in $Y$ is not to say that $X$ is a good-making feature of $Y$, nor that $X$ is important because it is a good-making feature of $Y$. Finally, to say that what participants in $Y$ regard as a good-making feature of $Y$ would not be possible unless $Y$ were $X$ is not to say that $X$ is a good-making feature of $Y$.

This last point is a crucial one to make on Raz's behalf, because a central tenet of his view is that law could not serve to guide people in their conduct unless the content of law were determinable in the way he says it has to be. Shapiro refines and extends the kernel of this Razian position, and so the point is crucial in defending his methodological posture, too.

10. Id. at 113-114.

11. SHAPIRO, supra note 1 , at 172-176.

12. Id. at $118-120$.

13. John Finnis, Law as Coordination, 2 RATIO JURIS 97-104 (1989).

14. DiCKSON, supra note 3 , at 114-128.

15. JOSEPH RAZ, The AuthORITY OF LAW (1979), at 50-52.

16. Dickson, supra note 3 , at 53-54. 
Taking Dickson's line, one would conclude that the distinctions just drawn show that it would be a mistake to think that Raz or like-minded others, such as Shapiro, are committed to the MET merely because of what they say about law's functions, despite their disavowing any such commitment. Raz's and Shapiro's accounts of law are, methodologically, instances of indirectly evaluative legal theory, which is the right kind of theory to be, on Dickson's account. No, I oversimplify. As Dickson explains it, the correctness of a methodological posture has to be judged, in the final accounting, in light of the adequacy of the substantive legal theories it allows one to formulateand she does not make that final accounting. ${ }^{17}$ But if a methodology led only to inadequate substantive theories, that fact would have to be a weighty or even decisive reason to reject it. Not to be overlooked, another reason to reject a methodology would be if one had to depart from it to make one's substantive theory adequate. That is the charge of which Raz should be acquitted, according to Dickson. ${ }^{18}$ Shapiro would also be acquitted, on the same ground.

This is all well and good. What I would like first to explore is the question of whether Dickson's statement of the MET is itself too coarse-grained, and whether a finer-grained pair of propositions would serve to further Dickson's wider enterprise, even if it possibly impedes her narrower aim of defending Raz against Dworkin. The refinement I suggest is to distinguish the following:

$M E T_{\text {weak }}$ : an adequate theory of law must morally evaluate law, that is, state what must be true if law is to make good its claim to moral authority.

$M E T_{\text {strong: }}$ an adequate theory of law must morally evaluate law, that is, state whether law in fact possesses the moral authority it claims.

What I want to do now is to explain the distinction between $\mathrm{MET}_{\text {weak }}$ and $\mathrm{MET}_{\text {strong. }} \mathrm{I}$ then argue that $\mathrm{MET}_{\text {weak }}$ is true and $\mathrm{MET}_{\text {strong }}$ is false. Raz and Shapiro are committed to $\mathrm{MET}_{\text {weak, }}$ Raz openly, Shapiro perhaps willy-

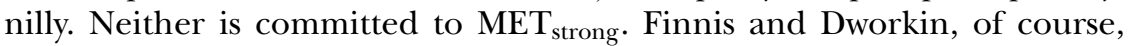
are committed to both $\mathrm{MET}_{\text {weak }}$ and $\mathrm{MET}_{\text {strong, }}$, if for no other reason than their explicit avowal of MJT-for MJT entails (but is not entailed by) $\mathrm{MET}_{\text {strong }}$ and $\mathrm{MET}_{\text {strong }}$ entails $\mathrm{MET}_{\text {weak }}$. I have nothing further here to say directly about their accounts, methodological or otherwise.

In fairness to Dickson, I should point out that she is aware of the distinction that $\mathrm{MET}_{\text {weak }}$ and $\mathrm{MET}_{\text {strong }}$ encapsulate. In the course of arguing against Finnis's claim that MET entails MJT, she writes:

[MET] states only that a legal theorist must take some stance on the moral value of the law in order to understand it adequately. Even if we interpret this as 
requiring that in order to understand law adequately, a legal theorist needs to take a stance on the conditions under which law would be justified, there is still a significant gap between this claim, and the further claim that [MJT] is true. ${ }^{19}$

Because $\mathrm{MET}_{\text {strong }}$ entails $\mathrm{MET}_{\text {weak }}$, it is a fortiori true that if $\mathrm{MET}_{\text {strong }}$ does not entail MJT, then MET $_{\text {weak }}$ does not entail MJT.

What I now want to explore is what it might mean to say that a legal theorist "needs to take a stance on the conditions under which law would be justified." ${ }^{20}$ Raz does in fact take such a stance: it is the well-known "normal justification thesis". ${ }^{21}$ The next question is whether such a stance is essential to the theorist's account of law, and if so, whether it is consistent with maintaining that one's theory of law is an indirectly evaluative rather than a directly evaluative legal theory. I argue that in both Raz's case and Shapiro's, a stance on what it takes to justify law is indeed needed in order to make their respective accounts adequate. Even so, given the way Dickson defines "directly evaluative" and "indirectly evaluative" propositions, ${ }^{22}$ neither Raz's nor Shapiro's are directly evaluative theories.

I then try to show that the distinction between the directly and the indirectly evaluative, as Dickson draws it, is not as significant as she believes. The underlying idea, however, is significant enough to maintain a line dividing $\mathrm{MET}_{\text {strong }}$ and $\mathrm{MET}_{\text {weak }}$.

I conclude by arguing that a commitment to MET $_{\text {weak }}$ already commits a legal theorist to engaging in political philosophy-up to a minimum that is well short of the entirety of the subject, however. And the commitment is, of course, not to be confused with the notion that every legal judgment is a political philosophical thesis, which is a notion that is almost as loony as thinking that every weather report is a proposition of quantum mechanics. Even so, the commitment is not trivial, as we see below. Raz takes on this responsibility, but—so far anyway-Shapiro has not.

\section{DOES AN ADEQUATE LEGAL THEORY NEED A THEORY OF LEGITIMACY?}

An adequate theory of law will account for its important features. These important features will include beliefs and attitudes that people commonly have about law. Law is a concept that is not the invention of theorists but is one that normal adults are not only familiar with but employ on a frequent if not everyday basis. It may be true, as Raz suggests, that a legal system might be present in a community of people who do not possess the concept

19. Id. at 73 (second emphasis added).

20. Id.

21. Joseph Raz, The Morality of Freedom (1986), at 53-57.

22. DiCKSON, supra note 3, at 51-53. 
themselves. ${ }^{23}$ Even so, surely the truisms current across communities that are in possession of both a legal system and a concept of law are of central significance (especially so if we take Raz's point that law is interesting because it is a part of how we understand ourselves).

How does a theorist compile what is commonly believed about law? Her own beliefs should count, after some light winnowing to remove those that are so theory-laden that it would be an error to suppose they are generally held. But a theorist's training and experience as a legal insider need not be discounted altogether. Sociological surveys, such as Tom Tyler's work on common attitudes toward the law and critiques thereof (especially by Leslie Green), ought to be consulted. ${ }^{24}$ Any compilation will reflect the resources, circumstances, and biases of the theorist, of course, which cannot be avoided but have to be borne in mind.

What will this yield? It is unlikely that any proposition will be universally credited; but if oddball, outlier, and ideologically infused dissents are ignored it would be surprising if there were no platitudes, or what Shapiro calls "truisms about law," to emerge. ${ }^{25}$ There do seem to be some likely truisms: for example, that people can be punished for disobeying the law, that laws often vary from place to place, and that legislatures pass laws, and so on. One problem remaining is that most of these beliefs can be variously expressed, and the theorist has to impose a canonical form. For example, the proposition that "law claims moral authority" is unlikely to have passed the lips of many people in that precise formulation. That should not stand in the way of the theorist if indeed it seems to be commonly believed that the law claims moral authority. At the intake stage, the theorist has to be allowed some liberty. But that liberty should not be abused, as it would be if, for example, something like "law is justified coercion" were simply presumed, without discussion, to be an important platitude.

Having canvassed what is commonly believed about law, how does a theorist determine which of those beliefs is important? At this point, the theorist's judgment of the importance of a truism can and should uncouple itself from folk intuitions about its importance. A useful way to proceed will be to sort through the truisms to look for conflicts among them. These conflicts between truisms will probably be of theoretical importance whether or not they are objects of folk remark and reflection. If such conflicts are actively disputed among the folk, they will probably be important to both the theorist of the practice and participants in it. For example, if "one ought to obey the law" looks truistic, but so does "the law is sometimes unfair," then the theorist has to decide whether one or the other need not be accounted for, or whether both can be accounted for by interpreting the two in a way

23. Joseph Raz, Can There Be a Theory of Law?, in The Blackwell Guide to the Philosophy OF LAW AND Legal TheORY (M. Golding \& W. Edmundson eds., 2005).

24. Tom R. Tyler, Why People Obey the LaW (1990); Leslie Green, Who Believes in Political Obligation?, in The Duty TO OBEY THE LAW (W. Edmundson ed., 1999).

25. SHAPIRO, supra note 1 , at 11-12. 
that eases the tension, as in "one ought to obey the law despite its being unfair," or "one ought to obey the law except when it is unfair." It cannot be the case that both of these propositions are truistic. But precisely because of the difficulty, both of the two initial propositions have to be considered important. The theorist thus has to deal with them.

One could deny that "one ought to obey the law" is a truism. It is possible to deny it without lapsing into nonsense talk, and indeed it has been denied, and denied even in qualified, weakened reformulations. Bear in mind, though, that a proposition does not cease to be truistic merely because it can be intelligibly doubted or denied. "One ought not to kill people" is truistic even though it has to be qualified before it can command the assent of scrupulous speakers. To insist that no proposition is a truism unless it is exceptionless would be to lose sight of what makes truisms worth accounting for. What makes them worth accounting for is that they anchor a concept that people use. Admittedly, there are formulations that are more acceptable than others. "One ought to obey the law unless there is a good reason not to" is perhaps the relevant truism.

One might also deny that "law is sometimes unfair" requires the theorist to address moral questions, because fairness is but a contingent feature of law. But it is a noncontingent feature of law that it is something that can be fair or unfair. Not everything is like this. It makes no sense to say that a kitchen table is fair or unfair, or that a gathering of people is fair or unfair. Given a made-up backstory, assertions like these might be given some sense. But that is not required when the subject is the law's fairness or unfairness. If we decompose "law" into "this law" and "that law," it seems truistic to say not only that this law is capable of being fair or unfair but that it is either fair or unfair.

The two prototruisms I am considering are both evaluative (I include the normative under this heading, just for the sake of convenience). No one would suggest that that in itself could be a ground for dismissing them as unimportant. On the contrary, evaluative beliefs about the law should count as very important. Evaluative beliefs have a bearing on how people should live their lives, and that is important. So this is how the theorist is drawn into the following difficulty: How is it possible to decide which of the various evaluative prototruisms believed about the practice by participants in the practice and intertwined with their participation in the practice are important enough to require accounting for, and which should be set aside as merely contingent, or noncontingent but inessential, or as folk notions that just do not make the cut? The difficulty is compounded by the fact that the supposed truisms will have been reformulated in an idiom that is congenial to theorizing but perhaps no longer colloquial.

The theorist might be confident that she can make these judgments "indirectly" without having to make direct judgments of the kind she may well have identified as among the prototruisms she needs to try to work up into an account of the concept of law. (Or the theorist might throw up 
her hands and throw in with Dworkin, professing that it is first-order, direct evaluation all the way up and all the way down.) But if the theorist believes that there are important truisms that have an evaluative cast, she will have to have something to say about what would make those evaluative truisms true. ${ }^{26}$ She will also have to say something in defense of her choice to dismiss evaluative prototruisms as merely proto- and thus as not belonging to the nature of law. But even that is not enough: she will have to explain how the dismissed candidate truisms might be false of law or, if not possibly false of law, then not of the essence of law.

What the theorist who wants to stay "indirect" has to do is to propose a theory of legitimacy, that is, a theory that explains what would have to be true to make the surviving recognized, evaluative truisms true. But the theorist has to do this, qua legal theorist, only if a theory of law is not adequate unless it states the truth grounds of the central truisms anchoring the concept of law. There does not seem to be any debate about this, though. And there does not seem to be any debating the fact that the concept of law that most people have in their heads is one that is intimately tied up with ideas of right, wrong, rights, duties, permissions, powers, immunities, and so forth-all in or intimately near a moral key.

The legal theorist whose aim is an adequate account of law's nature thus has no option but to set out an account of the truth grounds of at least the more central of the evaluative truisms about law. This account is a theory of legitimacy, that is, an account of what it would take to make these truisms true. ${ }^{27}$ This will encompass, centrally, an account of what would make law's claims to moral authority true (or why those claims are incapable of truth). The theory of legitimacy does not have to state whether those grounds in fact are present. The theory of legitimacy does not have to say whether law is morally legitimate or not: the legal theorist can and properly should reject $\mathrm{MET}_{\text {strong. }}$. But an adequate account of law's nature has to say something about what would make its characteristic claim to authority at least possibly true (or necessarily false).

\section{IS A THEORY OF LEGITIMACY DIRECTLY EVALUATIVE?}

The question, "Is a theory of legitimacy directly evaluative?"-meaning, is it necessarily directly evaluative-looks like an easy question to answer. A theory of legitimacy is directly evaluative if and only if one can validly detach from the theory some statement of the form "Legal systems are good" or "Legal systems possess good-making features." A legal theory containing a theory of legitimacy is directly evaluative if and only if either its theory of legitimacy or some other part of it is directly evaluative. I leave aside the possibility that some aspect of a legal theory other than its theory of legitimacy might

26. Bas van der Vossen prodded me to clarify this point.

27. See Edmundson, supra note 2, for a lengthier argument. 
be directly evaluative. (I cannot imagine what that would be without being something that would naturally come under the heading of a theory of legitimacy.)

A theory of legitimacy will state that a legal system has a certain evaluative property if (and perhaps only if) it has a certain set of descriptive properties. For example, Raz's normal justification thesis states that a person $A$ has legitimate authority over person $B$ if $B$ is likely better to comply with reasons already applying to $B$ if $B$ does what $A$ says rather than if $B$ acts on $B$ 's own judgment. ${ }^{28}$ There are complications here, as is well known. The "no 'ought' from an 'is'" issue, for one. The difference between a supervenience relation and an explanation is another. Put those aside. Whether a theory of legitimacy states necessary descriptive conditions, sufficient descriptive conditions, or necessary and sufficient descriptive conditions for a legal thing (authority, system, edict) to have an evaluative property, it states some connection between the descriptive and the evaluative. But it need not state that any legal thing has any evaluative property in the sense Dickson calls the directly evaluative sense. ${ }^{29}$ No direct evaluative conclusion is detachable from a theory of legitimacy per se, so long as we understand that no proposition is directly evaluative unless it is an atomic proposition predicating some evaluative property of a legal subject. Put it another way: as stated above, $\mathrm{MET}_{\text {weak }}$ does not entail MET $\mathrm{Mtrong}_{\text {. }}$

\section{DOES A THEORY OF LEGITIMACY CONTAIN MORAL JUDGMENTS?}

The question, "Is a theory of legitimacy directly evaluative?" is an easy question to answer because of the way "directly evaluative" is defined. We use Dickson's definition, and Dickson seems to assume that merely indirectly evaluative judgments are not moral judgments. But that seems very implausible as a general proposition. Consider the following sentence:

If there are any good men at all, Abraham Lincoln was a good man.

This sentence counts as indirectly evaluative, according to the Dickson definition, but it normally expresses a moral judgment. It does not state that Abraham Lincoln was a good man. But it does not merely conversationally imply that he was, either. ${ }^{30}$ Nor is it a tautology. It could be intelligibly denied, and in fact the goodness of Abraham Lincoln could be debated without using any simple subject-predicate sentences. Chestnuts like the

\footnotetext{
28. RAZ, supra note 21 , at 53.

29. Dickson, supra note 3 , at 51-53.

30. How would one cancel the implication? "If anyone was a good man, Abraham Lincoln was a good man, but-don't get me wrong-I'm not saying Abraham Lincoln was any good as a man," would hardly do. See Paul Grice, Studies in the Ways of Words 44-46 (1989).
} 
sentence above have been around for a while. ${ }^{31}$ What they tell us is that grammatical structure alone is no litmus test of whether a sentence expresses a moral proposition.

Granted, many indirectly evaluative statements merely report that certain direct evaluative judgments are in fact made, or, in consistency, ought to be made, by certain people. Raz emphasizes the category of what he calls "detached legal statements," by which the speaker reports that a normative system to which another subscribes has certain normative implications. ${ }^{32}$ The point I am making is not that indirect moral evaluative statements express, one and all, moral judgments. That would be false. The point rather is that any serious attempt to state the truth grounds of the kinds of evaluative statement necessary to legal theorizing is going to involve making some (probably controversial) moral judgments.

An example will help make the point more clearly. Consider abortion. This is a morally controversial topic if anything is-and in fact this is a morally controversial topic. Someone who preferred to stay out of the debate might say, "Well, I could be persuaded that abortion is wrong if I were persuaded that a fetus is a person." Or, "Even if a fetus is a person, for me it is still a further question whether it is a woman's right to choose." What people who say things like this are doing is exploring the truth grounds of directly evaluative statements; but they are not making directly evaluative statements. Even so, I think it is natural to say that they are making moral judgments even though they are not passing moral judgment. ${ }^{33}$ Not all moral judgments are moral verdicts.

Contrast this with someone who says, "Candidate $X$ is committed to saying that a woman has a right to abort a fetus because of its sex," or "abortion is not a big political issue in Europe." These not only are not directly evaluative statements, they really are detached, in the way the first two examples are not detached. Just for convenience, call the first pair framing judgments. They state logical relations between descriptive or quasi-descriptive judgments and directly evaluative judgments, but—by themselves - they are not directly evaluative and they do not entail directly evaluative judgments. But framing judgments are moral judgments. Or, I should say, pending further legislation about what counts as a moral judgment, framing judgments are moral judgments.

31. See David Rynin, The Autonomy of Morals, 66 Mind 308-317 (1957); A.N. Prior, The Autonomy of Ethics, 38 Australasian J. Phil. 199-206 (1960).

32. Joseph Raz, Practical Reason and Norms (2d ed. 1990), at 170-171, 172, 176-177; cf. Kevin Toh, Raz on Detachment, Acceptance, and Describability, 27 Oxford J. Legal Stud. 403-427 (2007).

33. I acknowledge that in some contexts a directly evaluative statement is implied by the use of a sentence that grammatically is merely indirectly evaluative. "If the butler did it, he ought to hang," uttered in circumstances in which it is obvious that the butler did do it, directly states that the butler ought to hang. The theory of legitimacy I refer to in the text is highly unlikely to be uttered in circumstances as plain as this, as regrettable as that may be. 
Stephen Perry's value-based conception of legitimate political authority is a case in point. Perry's favored statement of the conception is this:

one person $A$ has a power to effect a certain kind of change in the normative situation of another person $B$ if there is reason for regarding actions which $A$ takes with the intention of effecting a change of the relevant kind as in fact effecting such a change, where the justification for so regarding $A$ 's actions is the sufficiency of the value or desirability of enabling $A$ to make this kind of normative change by means of this kind of act. ${ }^{34}$

The placeholder for "value or desirability" makes this a framing judgment but not a directly normative judgment. According to Perry, "the value-based conception of a moral power is the conceptual core and, perhaps-depending on one's views about descriptive versus normative jurisprudence-also the moral core both of jurisprudence and of law itself." 35 Despite the reference to "moral core," Perry offers this as "a piece of normative-conceptual analysis" rather than a "substantive theory addressed to the justification problem [for] further moral argument is required to determine what kinds of value (if any) will justify $A$ 's possession of such a power as well as to determine the sufficiency of that value." 36

The "further moral argument" would, one would suppose, include or conclude with some directly normative judgments. But such judgments are not part of the value-based conception. Notice that the boundary between "normative-conceptual analysis," on the one hand, and "further moral argument to determine what kinds of value (if any)" can fill the place the analysis has created, on the other, is a porous one. ${ }^{37}$ Surely, normative-conceptual

34. Stephen R. Perry, Political Authority and Political Obligation, in 2 Oxford STudies In PhILOSOPHY OF LAW 82 (L. Green \& B. Leiter eds., 2013).

35. $I d$. at 88 .

36. $I d$. at 82 .

37. Joseph Raz makes a closely related point this way:

Accounts of "authority" attempt a double task. They are part of an attempt to make explicit elements of our common traditions, a highly prized activity in a culture which values self-awareness. At the same time such accounts take a position in the traditional debate about the precise connections between that and other concepts. They are partisan accounts furthering the cause of certain strands in the common tradition, by developing and producing new or newly recast arguments in their favor. The very activity is also an expression of faith in the tradition, of a willingness to understand oneself and the world in its terms and to carry on the argument, which in the area with which we are concerned is inescapably a normative argument, within the general framework defining the tradition. Faithfulness to the shape of common concepts is itself an act of normative significance.

Joseph Raz, Authority and Justification, 14 PhIL. \& PuB. AfF. 3-29 (1995), at 27-28. Raz's strict positivism as to the sources of law is in some tension with this (see David Plunkett, A Positivist Route for Explaining How Facts Make Law, 18 Legal THeORY 139-207 (2012), at 177-178 and n.90). If "normative argument, within the general framework" includes plumping for what I term "framing judgments," and if "law" can be substituted for "authority," the passage is a stirring endorsement of and suggestive argument for the $\mathrm{MET}_{\text {weak }}$. 
analysis can rule out certain candidate values, for example, the value of warm puppies or (a closer case?) of patriotic paraphernalia.

A theory of legitimacy necessarily includes framing judgments. To state truth grounds-partial or complete-for directly evaluative statements is to make a framing judgment. An adequate theory of law must contain a theory of legitimacy, which must consist in part of framing judgments, which are (pending further legislation) moral judgments (though not directly evaluative statements). Therefore, an adequate theory of law must make (some) moral judgments. MET $_{\text {weak }}$, in other words, is true, as I think I have just shown.

\section{THE WAGES OF FUNCTIONALISM}

We may distinguish two aspects of legal theory: the theory of legal content, and the theory of legal institutions. There are others, but I now focus on these. I assume that both the theory of legal institutions and the theory of legal content are in some sense and to some extent matters of conceptual analysis. Adopting the convention recommended by David Plunkett, ${ }^{38}$ I refer to the relevant concepts by the use of small capitals: LEGAL CONTENT and LEGAL INSTITUTION. A legal theorist might resolve to be a positivist about LEGAL CONTENT and at the same time an antipositivist about LEGAL INSTITUTION. Shapiro's Legality places LAW in the genus COMPREHENSIVE PLANNING ORGANIZATION, and adds several differentiae: SELF-CERTIFYING, COMPULSORY, AIMING TO SOLVE CERTAIN MORAL PROBLEMS. In my review of Legality, I argued that including the moral-aim differentia makes the planning theory a kind of moral-functionalist theory of law and that-as such-it comes within the ambit of the weak natural law thesis propounded by Mark Murphy and John Finnis. ${ }^{39}$ In other words, Shapiro's account of LEGAL INSTITUTION is antipositivist. I also argue there that that affinity creates difficulties for Shapiro's positivism about LEGAL CONTENT. ${ }^{40}$

In a recent article in this journal, David Plunkett writes approvingly of Shapiro's account of LEGAL CONTENT and suggests that Shapiro has located conceptual linkages between LEGAL CONTENT and LEGAL INSTITUTION that make trouble for antipositivists like Mark Greenberg. ${ }^{41}$ Thus, Plunkett:

At the core of Shapiro's argument ... is a crucial connection between the concepts LEGAL NORM and LEGAL INSTITUTION. In short, the connection is roughly

38. Plunkett, supra note 37 , at 142 n.5.

39. Edmundson, supra note 2; cf. Mark C. Murphy, Natural Law Theory, in The Blackwell Guide to the Philosophy of LaW and Legal Theory (M. Golding \& W. Edmundson eds., 2005).

40. Edmundson, supra note 2.

41. Mark Greenberg, How Facts Make Law, in ExPloring LAW'S EMPIRE: THe JurisPrudence OF RONALD DWORKIn 225-264 (Scott Hershovitz ed., 2006); Mark Greenberg, Hartian Positivism and Normative Facts: How Facts Make Law II, in ExPLORIng LAW'S EMPIRE: THE JurisPrudenCE OF RONALD DWORKIN 265-290 (Scott Hershovitz ed., 2006). 
this: it is a conceptual fact that legal norms are norms that are produced by or endorsed by legal institutions in a particular way.... Something like this is, I think, a basic conceptual truth. ${ }^{42}$

On Plunkett's understanding, LEGAL NORM and LEGAL CONTENT are nearly interchangeable concepts, for legal contents are norms. ${ }^{43}$ According to Plunkett, antipositivists have to offer a plausible account of LEGAL INSTITUTION, and they will encounter at least two difficulties.

The first difficulty is the intuition prevalent among ordinary people, anthropologists, and historians that they can tell whether something is or is not a legal institution (namely, is or is not within the extension of LEGAL INSTITUTION) without having first to evaluate it morally. The second difficulty is that, assuming the success of Shapiro's positivist account of LEGAL CONTENT, the antipositivist has to explain why what is sauce for the LEGAL CONTENT goose is not sauce for the LEGAL INSTITUTION gander. After all, whatever institutions instance the concept LEGAL INSTITUTION do so in virtue of their relation to the instances of LEGAL CONTENT they generate or subsume.

It is ironic that Plunkett ascribes the first of these difficulties to antipositivism: Shapiro's account of LEGAL INSTITUTION classes it as a concept "that we use only for institutions that play a certain functional role," ${ }^{44}$ which for Shapiro is characterized by its moral aim, and Shapiro himself is thus, pro tanto, an antipositivist. "If we want to explain what makes the law the law, we must see it as necessarily having a moral aim," Shapiro writes. ${ }^{45}$ An institution that lacks the aim does not fail in the role: it does not play the role at all.

The second difficulty is one that can cut either way. Suppose the conceptual links between LEGAL CONTENT and LEGAL INSTITUTION are as tight and plentiful as Plunkett suggests, invoking Shapiro's planning theory. If that is so, then if there is a persuasive antipositivist account of the concept of LEGAL INSTITUTION, it would automatically create a difficulty for positivism about LEGAL CONTENT. If the links are there, they run in both directions. Plunkett suggests that some antipositivistic-sounding remarks of Raz's about AUTHORITY (viz., those quoted in note 37, supra) create tension with Raz's staunch positivism about LEGAL CONTENT. If there is such a tension in Raz's writings, it is present in Shapiro's also.

How serious is the tension within the planning theory? My earliest thought was that it is an illusion: it is perfectly consistent to be a thoroughgoing positivist about LEGAL CONTENT and an antipositivist about LEGAL INSTITUTION. Suppose there is an organization created to pursue moral aims: call it the Moral Aim Society. Suppose its charter and by-laws make it clear that the Society is dissolved the moment its members cease to pursue certain moral

42. Plunkett, supra note 37 , at 198.

43. Id. at 176 .

44. Id. at 204.

45. SHAPIRO, supra note 1 , at 215. 
aims. (It lacks some other indicia that, all taken together, would make it a legal institution: it is not self-certifying or perhaps is ineffective). The Moral Aim Society, like most other organizations, also makes plans. Not every plan that a Moral Aim Society makes has, itself, got to have a moral aim, any more than every plan made by a legal institution has to be a law. There is no reason the Moral Aim Society could not make plans whose content was identifiable without recourse to moral reasoning. The Moral Aim Society plans an annual picnic, for example. There is no reason to hesitate to say that the Moral Aim Society is essentially an institution pursuing certain moral aims and generating a plan whose content is fully determined by nonmoral facts. Moral argument might be needed to determine whether those aims are in fact moral, but there is no need to resort to moral argument to determine what the content of its picnic plans are.

This argument should not persuade anyone. It is unlikely that any planning organization whose raison d'être is to address certain moral problems, as such, will forever tiptoe around those problems without ever getting down to addressing them. And whether it is or is not getting down to the taskor trying to-will indeed involve moral recognition and argumentation. At some point, one might have to say that the Moral Aim Society never got going-either that, or to take the "moral aim" as designating whatever aims the organization in fact pursues and purports to regard as moral.

The counterpart of this move for planning theory would be to say that the moral aim distinctive of instances of LEGAL INSTITUTION is tied to some positive or relativized notion of morality. But in that case, Shapiro's evident ambition nonarbitrarily to disqualify the mafia as a candidate LEGAL INSTITUTION will go by the board. ${ }^{46}$ For it would mean that the Gunman Writ Large gets admitted as an instance of LEGAL INSTITUTION, which is an admission that legal positivists from Austin to Kelsen to Hart almost never seem willing to make. $^{47}$

I see one remaining way to hang onto both antipositivism about LEGAL INSTITUTION and positivism about LEGAL NORM. Often, we are clear about the content of a norm well before we are confident about where it came from. The epithet "legal" (like "valid") has an honorific connotation when applied to an institution; but we have trained our ears to ignore that connotation when "legal" (or "valid") is applied to the norms the institution encompasses. At least since Kelsen, we have also been accustomed to thinking that legal contents- “valid" legal norms_can exist only within a legal container, that is, a legal system or institution. This seems entirely sensible until we confront questions like, "Did the Third Reich have a law of contract?" Is it

46. Cf. my discussion in Edmundson, supra note 2.

47. But there is a small coalition of the willing. See Matthew Kramer, Scrupulousness without Scruples: a Critique of Lon Fuller and His Defenders, 18 OXFORD Journal OF Legal STUdies 23564 (1998); Kenneth E. Himma, Law's Claim of Legitimate Authority, In J. Coleman, ED. HarT's Postscript: Essays on the Postscript to The ConcePt OF LAW (2001). 
crazy to suggest that German contract law during that period was a case of legal norms in search of a legal system?

It is no more crazy than it is to admit customary norms-those planlike norms that are not planned-as legal norms, without benefit of ceremony. CUSTOM, like PLAN but unlike LEGAL INSTITUTION, need not involve any moral aim. If something, as an instance of CUSTOM unbeholden to any sort of LEGAL INSTITUTION, can nonetheless count as an instance of LEGAL NORM (but not of LEGAL CONTENT, for where is the container?), then an antipositivist about LEGAL INSTITUTION can securely profess positivism as to certain legal norms. An antipositivist about LEGAL INSTITUTION can be a positivist about legal norms having customary status and legal norms that have passed or are passing through failed examples of LEGAL INSTITUTION. But insofar as LEGAL CONTENT is conceptually bound to LEGAL INSTITUTION, antipositivism as to one spells antipositivism as to the other. Moral facts might be entirely unnecessary to identifying plan content, just as in the case of the Moral Aim Society's annual picnic. But moral facts are necessary part-determinants of what can and what cannot count as instancing LEGAL INSTITUTION, and so also of which plans do and which do not count as instances of LEGAL CONTENT. Moreover, a moral-aim functionalist about LEGAL INSTITUTION has to face the question: how is one to distinguish mere CUSTOMARY NORM from CUSTOMARY LEGAL NORM? If a moral-aim differentia of CUSTOMARY LEGAL NORM is admitted, then the theory is no longer a legal positivism about LEGAL NORM or LEGAL CONTENT.

\section{CONCLUSION}

In closing, I would like once more to emphasize a responsibility that legal theorists take upon themselves but, it seems to me, currently too often tend to neglect. The most outstanding anglophone legal theorists of this century-Raz, Finnis, and Dworkin-do not neglect this responsibility, and that fact is in no small measure why they are the most outstanding. It is the legal theorist's responsibility to set out and defend a theory of legitimacy. The autonomy of jurisprudence is a delusion if it means denying this responsibility. The needed task necessarily involves the legal theorist in political philosophy, but that is nothing to be regretted or ashamed of. 